\title{
Cesarean sections at all-time high
}

More than 1 in 5 Canadian babies are now arriving via cesarean section - an all-time high - and fewer family doctors are attending births, says a new I report by the Canadian Institute o for Health Information (CIHI).

In $2001-02,22.5 \%$ of babies delivered in hospital were born by cesarean section, up from 15\% in 1979-80, says Giving Birth in Canada: Providers of $M a-$ ○ ternity and Infant Care. Although

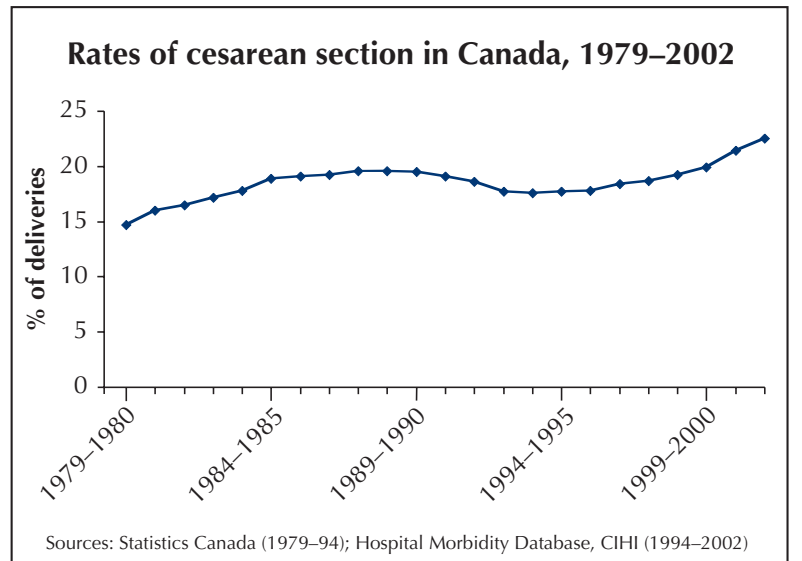

the report does not explain the increase, it points out that more women aged 30 and over are having babies, fertility drugs are producing more multiple births, and high-risk pregnancies now comprise $10 \%$ of all deliveries.

In the early 1980 s, health-care providers encouraged mothers who had delivered one child by cesarean section to try for a vaginal birth in subsequent pregnancies, says Kira Leeb, manager of health reports for the CIHI. "What we see [now] is almost a direct correlation between a decrease in the rate of vaginal births after C-sections and an increase in C-sections."

At the same time, fewer family physicians are providing obstetrical services - just $16 \%$ in 2001 , compared with $31 \%$ in 1989 , according to billing data from provincial health insurance plans. Those family doctors who do attend deliveries are not doing the honours for cesareans and multiple births, the report indicates.
Only $5 \%$ of family physicians delivered babies via cesarean section in 2000 , down from $7 \%$ in 1996 ; just $3 \%$ of multiple births were attended by family doctors in 2002, down from 6\% in 1994. When surveyed about why they aren't delivering more babies, family physicians cite concerns about lifestyle, malpractice and the skill level required.

Obstetricians are filling the gap, attending $95 \%$ of all cesarean sections in 2002, $96 \%$ of all multiple births and $61 \%$ of vaginal births. The numbers come as no surprise to the Society of Obstetricians and Gynaecologists of Canada, which says the decline in the number of family physicians performing deliveries is contributing to an "obstetrical crisis." Over the next 5 years, more than one-third of obstetricians and gynaecologists in Canada plan to retire, the society says, suggesting an imminent shortage of these specialists. - Laura Eggertson, CMAJ 